\title{
FORMAÇÃO DE PROFESSORES NO INSTITUTO FEDERAL DO PARANÁ: DILEMAS FORMATIVOS ${ }^{1}$
}

\author{
FORMACIÓN DEL PROFESORADO EN EL INSTITUTO FEDERAL DE PARANÁ: \\ DILEMAS FORMATIVOS
}

\author{
TEACHER TRAINING IN THE FEDERAL INSTITUTE OF PARANÁ: FORMATIVE \\ DILEMMAS
}

\author{
José Mateus BIDO ${ }^{2}$ \\ Maria Terezinha Bellanda GALUCH ${ }^{3}$ \\ Analice CZYZEWSKI ${ }^{4}$
}

RESUMO: A formação inicial e continuada de professores foi instituída como política educacional com a Lei n. ${ }^{\circ} 11.502$, de julho de 2007; a criação da Rede Federal de ensino faz parte das ações propostas para a oferta dessa formação. Este artigo tem como objetivo refletir sobre a formação inicial de professores proposta pelo Instituto Federal do Paraná (IFPR). Analisam-se Projetos Pedagógicos de Cursos (PPCs) de Licenciatura em Química e em Física do IFPR, mediante conceitos da Teoria Crítica da Sociedade. Observam-se nesses projetos ambiguidades que perpassam a perspectiva de formação humana no contexto da sociedade industrial desenvolvida, remetendo à compreensão dos limites da formação para a autonomia em um contexto heterônomo.

PALAVRAS-CHAVE: Formação de professores. Instituto Federal do Paraná. Teoria crítica da sociedade. Políticas públicas.

RESUMEN: La formación inicial y continua de profesores ha sido instituida como política educacional con la Ley $n .^{\circ} 11.502$, de julio de 2007; la creación de la Red Federal de enseñanza hace parte de las acciones propuestas para la oferta de esta formación. Este artículo tiene como objetivo reflexionar sobre la formación inicial de profesores propuesta por el Instituto Federal de Paraná (IFPR). Se analizan Proyectos Pedagógicos de Carreras (PPCs) de Profesorado en Química y en Física del IFPR, mediante conceptos de la Teoría Crítica de la Sociedad. Se observan en estos proyectos ambigüedades que traspasan la perspectiva de formación humana en el contexto de la sociedad industrial desarrollada, remetiendo a la comprensión de los límites de la formación para la autonomía en un contexto heterónomo.

\footnotetext{
${ }^{1}$ Artigo elaborado a partir da tese de doutorado defendida no Programa de Pós-Graduação em Educação da UEM, por José Mateus Bido, sob a orientação da professora Maria Terezinha Bellanda Galuch.

${ }^{2}$ Instituto Federal do Paraná (IFPR), Goioerê - PR - Brasil. Professor. ORCID: https://orcid.org/0000-0002-74323123. Lattes: http://lattes.cnpq.br/2760824691205280. E-mail: jose.bido@ifpr.edu.br

${ }^{3}$ Universidade Estadual de Maringá (UEM), Maringá - PR - Brasil. Professora do Departamento de Teoria e Prática da Educação e do Programa de Pós-Graduação em Educação. ORCID: https://orcid.org/0000-0001-51549819. Lattes: http://lattes.cnpq.br/4862416685441579. E-mail: mtbgaluch@uem.br

${ }^{4}$ Universidade Estadual de Maringá (UEM), Maringá - PR - Brasil. Professora do Departamento de Fundamentos da Educação. ORCID: https://orcid.org/0000-0003-0879-7336. Lattes: http://lattes.cnpq.br/5203271085339006. E-mail: aczyzewski2@uem.br

RIAEE - Revista Ibero-Americana de Estudos em Educação, Araraquara, v. 14, n. esp. 4, p. 2017-2031, dez., 2019. E-ISSN: $1982-5587$. DOI: https://doi.org/10.21723/riaee.v14iesp.4.12925 
PALABRAS CLAVE: Formación del profesorado. Instituto Federal do Paraná. Teoría crítica de la sociedad. Políticas públicas.

ABSTRACT: Initial and continuing teacher training was instituted as an educational policy under Law No. 11,502 of July 2007; The creation of the Federal Education Network is part of the actions proposed for offering this training. This article aims to reflect on the initial teacher education proposed by the Federal Institute of Paraná(IFPR). Pedagogical Projects of Degree Courses (PPCs) in Chemistry and Physics of IFPR are analyzed through concepts of the Critical Theory of Society. These projects present ambiguities that permeate the perspective of human formation in the context of the developed industrial society, referring to the understanding of the limits of training for autonomy in a heteronomous context.

KEYWORDS: Teacher training. Federal Institute of Paraná. Critical theory of Society. Public policies.

\section{Introdução}

Com a Lei n. ${ }^{\circ} 11.502$, de julho de 2007, a Coordenação de Aperfeiçoamento de Pessoal de Nível Superior (Capes) passou a ser responsável pela articulação, pela formulação e pela execução de políticas para atender à formação inicial e à formação continuada de professores para a educação básica e para o ensino superior. No que se refere à execução e à implementação dessas políticas, a regra é a do regime de colaboração ${ }^{5}$ entre os entes federados, mediante o estabelecimento de convênios com instituições de ensino superior e instituições privadas que atuam na área da educação. A referida lei foi criada com o objetivo de assegurar a qualidade e a expansão da formação dos profissionais que, prioritariamente, atuarão na educação básica e na superior.

Uma breve retomada acerca da complexidade dessa temática permite-nos apontar que esse debate não se limita aos dias atuais. Já na década de 1930, o Manifesto dos Pioneiros da Educação Nova, documento representativo do panorama educacional daquele contexto, apontava para a necessidade de estabelecer a "unidade na formação dos professores”, por estes serem os profissionais que conduzem a prática educativa nas escolas.

Sem negar a sua importância, o contorno jurídico não é suficiente para o estabelecimento de uma política que garanta programas de qualidade para atender à demanda de formação de professores. O Plano Nacional de Educação (PNE/2014-2024), por meio da sua meta 15

${ }^{5}$ De acordo com a LDB n. ${ }^{\circ}$ 9.394/96, Art. 8. ${ }^{\circ}$, a educação nacional deve organizar seus sistemas de ensino em regime de colaboração, entre a União, os estados, os municípios e o Distrito Federal.

RIAEE - Revista Ibero-Americana de Estudos em Educação, Araraquara, v. 14, n. esp. 4, p. 2017-2031, dez., 2019. E-ISSN: 1982-5587. DOI: https://doi.org/10.21723/riaee.v14iesp.4.12925 
(BRASIL, 2014, p. 78), aponta que a formação de professores é uma questão ainda não resolvida no Brasil, ou seja, ainda não há uma política de Estado constituída para essa finalidade. Dentre as estratégias indicadas como possibilidade para a solução desse problema, está à implementação de programas que assegurem a formação de professores em nível superior.

Nesse sentido, observa-se que a partir da década de 1990 houve a adesão por parte do Estado brasileiro às orientações contidas em relatórios técnicos formulados por organizações internacionais, que apresentam parâmetros para o perfil do profissional da educação básica. Contudo, a formação de professores torna-se mecanismo de controle quando alinha-se aos interesses governamentais; ao não se constituir como Política de Estado, pode ser descontinuada quando não estiver adequada a objetivos governamentais de um período; em geral, expressa estratégias para permitir a expansão do capital.

No contexto de necessidade de atender à demanda de formação de professores, o Ministério da Educação (MEC) viabilizou a criação da Rede Federal de Educação Profissional e Tecnológica, por meio da implantação dos Institutos Federais (IFs) que desenvolvem, gratuitamente, uma das etapas da educação básica - ensino médio propedêutico e ensino médio técnico -, a formação inicial de professores em nível superior e a formação continuada para docentes. Ainda que a justificativa original para a sua criação se assente na superação da formação meramente tecnicista (BRASIL, 2010), operacionalmente, o Instituto Federal é uma instituição formadora de profissionais, dentre os quais professores para a atuação na educação básica, cujo perfil atrela-se ao requerido pela sociedade industrial desenvolvida, em estágio avançado de desenvolvimento tecnológico.

\section{A institucionalização do Instituto Federal do Paraná (IFPR) e o seu dilema formativo}

O Instituto Federal do Paraná (IFPR) é uma instituição pública federal de ensino vinculada ao Ministério da Educação (MEC) por meio da Secretaria de Educação Profissional e Tecnológica (Setec) (IFPR-REITORIA, 2018). Foi criado em 29 de dezembro de 2008, por meio da Lei n. ${ }^{\circ}$ 11.892, que instituiu - a partir da Escola Técnica da Universidade Federal do Paraná (ET-UFPR) - a Rede Federal de Educação Profissional e Tecnológica e os atuais 38 institutos federais, cabendo-lhe a imputação legal de ofertar a educação básica e a profissional, bem como a educação superior. 
Se é possível ler na institucionalização dos IFs um projeto de formação integral (BRASIL, 2007), com incentivo à emancipação e à autonomia humanas, cabe uma reflexão crítica sobre a educação. Segundo Adorno (2006, p. 143),

A educação seria impotente e ideológica se ignorasse o objetivo da adaptação e não preparasse os homens para se orientarem no mundo. Porém ela seria igualmente questionável se ficasse nisto, produzindo nada além de well adjusted people, pessoas bem ajustadas, em consequência do que a situação existente se impõe precisamente no que tem de pior.

Nesse aspecto, tanto a educação que se limita à formação intelectual, quanto aquela que busca a inclusão por meio da formação de habilidades técnicas para a atuação imediata no mundo do trabalho, acabam educando pessoas tão somente bem ajustadas à realidade sem interpretá-la. Formar criticamente para agir produtivamente na sociedade é uma integração necessária; não se pode desconsiderar a necessidade de salvaguardar historicamente ao sujeito a possibilidade de se orientar na vida (ADORNO, 2008) ${ }^{6}$, entretanto se o sujeito não desenvolver a consciência da pressão que a sociedade exerce sobre ele, ser-lhe-á difícil pensar sobre a possibilidade de uma sociedade democrática, orientada pela e para a liberdade. Pensar uma formação para a emancipação é pensá-la revestida das condições políticas, sociais e econômicas que envolvem historicamente os indivíduos. Essa é uma análise reflexiva que se imputa aos IFs, no sentido de evidenciar o seu real propósito formativo (CIAVATTA, 2012).

Nesses termos, a crítica a respeito da formação docente, especificamente acerca da formação pretendida e da formação realizada no IFPR, não pode desviar-se da proposta de superação da condição humana que, política, social e economicamente, encontra-se reificada (COHN, 1986; WIGGERSHAUS, 2006).

Ao investigar-se a conjuntura institucional dos IFs, percebe-se que o encaminhamento do processo educacional destaca o trabalho como referência do processo educativo, sendo um dos meios de orientação do humano no mundo (BRASIL, 2010; 2007). Todavia, o trabalho há que ser entendido no seu vínculo com a realidade social de prevalência no capital. Ao abordar a concepção do trabalho capitalista, Marcuse (1973, p. 45, grifo do autor) o qualifica como processo de escravidão profissional. Para ele,

A máquina afirma sua maior dominação ao reduzir a 'autonomia profissional' do trabalhador integrando-o com outras profissões que sofrem e dirigem o conjunto técnico, no quanto se torna, ela própria, um sistema de ferramentas e relações mecânicas, indo, assim, mais além do processo de trabalho

${ }^{6}$ Nos registros das aulas proferidas no último curso ministrado por Adorno, os quais estão reunidos na obra Introdução à Sociologia, especialmente na $4 .^{\mathrm{a}}$ aula -2.5 .1968 -, o pensador manifesta a sua posição filosófica para fortalecer o sentido da prática social (ADORNO, 2008a, p. 98-99).

RIAEE - Revista Ibero-Americana de Estudos em Educação, Araraquara, v. 14, n. esp. 4, p. 2017-2031, dez., 2019. E-ISSN: $1982-5587$. 
individual. Na verdade, a autonomia 'profissional', anterior do trabalhador era, antes, sua escravidão profissional. Mas esse modo específico de escravidão era, ao mesmo tempo, a fronte de seu poder específico, profissional de negação - o poder de parar um processo que o ameaçava de aniquilamento como ser humano. Agora o trabalhador está perdendo a autonomia profissional que o faz membro de uma classe destacada de outros grupos ocupacionais por personificar a refutação da sociedade estabelecida.

É evidente o desafio do pensamento crítico na produção científica em uma sociedade cuja crítica formativa não se consolida como um valor cultural. Em uma cultura na qual o conhecimento científico serve ao exercício e à manutenção do poder (MARCUSE, 2009), a possibilidade do elemento crítico é fator de resistência pela própria oportunidade da reflexão. Nesse aspecto, faz parte da formação cultural a abertura à crítica autorreflexiva.

Como a criação dos IFs ocorreu em um país classificado pelas potências econômicas internacionais como um país em desenvolvimento, isto é, como aquele que ainda não atingiu a sua autonomia intelectual-formativa e econômico-financeira - critério pelo qual a identidade e o potencial de um povo são avaliados intencional e internacionalmente -, pensar a institucionalidade do IFPR é pensá-la no interior de uma economia política que estabelece as regras do sistema vigente. Assim, a instituição é aceita pelo sistema, mas é pressionada para não romper com a ordem econômica que o legitima, pelo emprego do discurso oficial assumido com roupagem inovadora.

As forças externas à instituição que se propõem a formar criticamente visam torná-la ineficiente; por outro lado, as forças internas buscam, preponderantemente, a crítica educacional que põe em questão as reais condições formativas imperantes no sistema em que historicamente uma instituição formadora está inserida. Pensar e agir para efetivar possíveis mudanças requer dos agentes ligados à instituição atitudes críticas e autorreflexivas sobre aquilo que impede os sujeitos de realizarem, em si e a partir de si, a humanidade à qual cada um está potencialmente ligado; requer, ainda, a conquista de uma formação que possa exercer resistência à sociedade do poder, em vez de ter como meta oferecer condições para a inclusão por meio da igualdade de poder.

A resistência está na concepção, no encaminhamento e na prática do processo educacional que fundamenta a racionalidade crítica para além da racionalidade instrumental e positiva fundada no princípio científico pragmático ${ }^{7}$. O potencial crítico apresentado pelos IFs

${ }^{7}$ Cabe dizer que o processo formativo refere-se à apreensão e à produção de conhecimento social, político e culturalmente constituídos. Trata-se da constituição imanente à autenticidade ou característica de um povo. Os distintos conhecimentos produzidos, postos a serviço do ser humano, constituem-se em formação cultural. Quando eles desproveem as pessoas de sua condição de ser, tornam-se conhecimentos que se esvaziam de sua finalidade, constituindo-se em meios para a reificação.

RIAEE - Revista Ibero-Americana de Estudos em Educação, Araraquara, v. 14, n. esp. 4, p. 2017-2031, dez., 2019. E-ISSN: $1982-5587$. 
e pelo IFPR - ao se abrir para a formação de uma racionalidade e de uma experiência cidadã que compreendem o humano e o trabalho mediante a condição alienada na qual se encontram - pode ter efeito se estabelecer um horizonte formativo e uma perspectiva de sociedade distintos do imperante. Formar científica e criticamente é apresentar aquilo que deforma; é compreender os mecanismos utilizados pela sociedade para manter os sujeitos sob a ameaça de não serem incluídos, bem como a possibilidade de superação dessa forma de existência. A formação cujo projeto de vida humana seja distinto dos que se apresentaram na história da educação brasileira significa uma perspectiva educacional para além dos modelos educativos internacionalmente pensados. Nesse sentido, a análise sobre a formação de professores no Brasil e, especialmente no IFPR, requer a leitura crítica que não se orienta pela desqualificação do valor da formação docente, mas para a argumentação contraditória sobre a realidade.

Feitas tais considerações, no próximo tópico, discute-se a formação de professores proposta pelo IFPR, mediante a análise crítica de projetos pedagógicos de cursos (PPCs) de licenciatura em Química e em Física do IFPR, destacando nesses projetos, ambiguidades que perpassam as propostas de formação de professores no contexto da sociedade industrial desenvolvida. A reflexão crítica pode ser a possibilidade de se pensar a formação para a autonomia, sem que signifique a formação para a perpetuação da heteronomia.

\section{Projetos Pedagógicos de Cursos de Licenciatura como expressão de proposta para formação de professores no Instituto Federal do Paraná}

Como já mencionado neste texto, nos PPCs de cursos de licenciatura em Química e em Física do IFPR (BIDO, 2018, p. 159-260) busca-se analisar a formação de professores proposta pelo IFPR. Isso demanda a compreensão, quando menos de três aspectos da formação docente, a saber: a relação didático-pedagógica; a dicotomia entre o conteúdo e a forma; a ruptura e a permanência na concepção de formação.

Para a análise, foram reunidos seis PPCs em desenvolvimento, sendo dois de licenciatura em Química e quatro de licenciatura em Física. O recorte leva em consideração um dos motivos que fundamentam os IFs: atender às áreas que possuem maior demanda por docentes nas escolas públicas.

A reflexão sobre os fundamentos e as finalidades que orientam a dinâmica social, para além da sua mera descrição, é imprescindível quando se quer chegar à relação entre a sociedade e suas instituições que, apesar de se mostrarem inovadoras, não raro, ocultam o seu caráter 
reacionário, já que buscam a positivização da realidade, em vez de mostrar a necessidade de superação visando uma organização em que todos possam viver dignamente, de acordo com as condições históricas e não as de poder.

Como evidência de ideias formativas que perpassam os PPCs, acentuam-se, em sua estrutura documental, cinco noções de formação: a) formação como "competências para ensinar" e para "propor métodos de ensino inovadores"; b) a formação como "consciência da função social do professor" para "integrar seus alunos na sociedade contemporânea"; c) a formação como "pesquisador"; d) a formação que "contempla tanto a formação teórica, científica e tecnológica, como também a formação humanística e pedagógica crítica”; e) a formação como desenvolvimento de "competências e habilidades necessárias ao futuro professor", estimuladas por meio do "aprendizado na perspectiva da interface e da transversalidade" entre "diversos campos de saberes e das tecnologias a eles correspondentes", com o propósito "à formação da cidadania universal e da formação profissional".

Diagnosticadas as cinco concepções de formação, ressalta-se que elas estão em plena sintonia com a conjuntura educativa oficial e, como tal, tornando-se reguladora da ação formativa para a funcionabilidade e a instrumentalidade racionais. Em foco está a pedagogia do aprender a aprender (DELORS, 1998, p. 92) e das competências (BANCO MUNDIAL, 2011, p. 7), o que reforça a flexibilização formativa (DELORS, 1998, p. 144) própria do contexto da sociedade industrial cujos processos de produção, o tempo e o espaço também se flexibilizaram diante do desenvolvimento científico e tecnológico que, a rigor, está acompanhada da regressão humana.

Sublinha-se que as condições formativas esboçadas nas cinco noções de formação reforçam mais os saberes operacionais do que o conhecimento aprofundado, denunciando o estímulo de uma racionalidade funcional e instrumental. Por outro lado, ao abordar o sentido da "formação da cidadania universal", aproxima-se do conceito de educação assumido por Edgar Morin (2003), limitando a noção de educação como formação cultural e direcionando o conhecimento para a atuação do homem no cotidiano, preparando-o como um profissional de especificidade, como também da proposta assumida pelo Relatório da Unesco (DELORS, 1998, p. 96).

A formação cultural, que compreende o homem como ser integral, está sendo substituída pela educação para as produções e saberes específicos. Quanto mais se especializa, mais a compreensão da totalidade é sacrificada, já que a especialização é a demandada pela lógica reguladora da pseudoformação. Observa-se que a formação docente, assumida como 
“competências para ensinar" e para "propor métodos de ensino inovadores” (IFPR/IVAIPORÃ, 2015, p. 11) reforça a forma, sendo que o conteúdo é posto para essa finalidade.

Ao tratar a formação como "consciência da função social do professor" para "integrar seus alunos na sociedade contemporânea” (IFPR/PARANAGUÁ, 2013, p. 4), a análise crítica se coloca para o entendimento sobre a distinção entre a análise aprofundada e o princípio do ajustamento sócio produtivo. Esse dado é determinante, visto que a autorreflexão se volta para a consciência formativa da ressignificação do humano ou para a sua reificação social.

A formação do professor, entendido como pesquisador - mesmo que o argumento venha reforçar o sentido da pesquisa contínua como meio de "contribuir para a sua área de ensino compartilhando suas experiências em sala de aula na forma de publicação científica" (IFPR/TELÊMACO BORBA, 2016, p. 11) -, expressa também o sentido de uma produtividade profissional ligada às metas propostas por indicadores científicos. Não se nega a importância da pesquisa, tampouco a desqualifica; a questão é a sua finalidade, visto que o sentido contemporâneo da ciência a coloca como reguladora da sociedade hegemônica.

Ao encarar a formação como aquela que "contempla tanto a formação teórica, científica e tecnológica, como também a formação humanística e pedagógica crítica", enuncia-se uma possibilidade de formação ampliada. Entretanto, a concepção formativa direciona a sua perspectiva para o "aperfeiçoamento humano e social” (IFPR/FOZ DO IGUAÇU, 2013, p. 13). Uma formação que se dirige ao "aperfeiçoamento humano e social" esboça o princípio funcional da adaptabilidade do profissional docente ao meio e do seu trabalho como meio de resposta aos desafios socioculturais.

Assumindo a formação como desenvolvimento de "competências e habilidades necessárias ao futuro professor", estimuladas por meio do "aprendizado na perspectiva da interface e da transversalidade" entre "diversos campos de saberes e das tecnologias a eles correspondentes”, com o propósito “à formação da cidadania universal e da formação profissional” (IFPR/JACAREZINHO, 2014, p. 8), fortalece-se o argumento oficial das Diretrizes Curriculares para Formação de Professores da Educação Básica. Sem ferir a base legal, a formação se encaminha como reguladora da dinâmica social desprovida da crítica dialética aos fatores sócio-políticos que confluem para a manutenção do status quo, atendendo inclusive às orientações das organizações internacionais.

Tomando-se as cinco noções de formação que se evidenciam nos PPCs, pela perspectiva da reflexão crítica, é possível diagnosticar a concepção pedagógica que contempla os rumos formativos. Esta se coloca em conformidade com a ideologia formativa que sustenta as orientações nacionais e internacionais sobre a educação, fortalecendo a pseudocultura. Mesmo RIAEE - Revista Ibero-Americana de Estudos em Educação, Araraquara, v. 14, n. esp. 4, p. 2017-2031, dez., 2019. E-ISSN: $1982-5587$.
DOI: https://doi.org/10.21723/riaee.v14iesp.4.12925 
que no texto existam conotações linguísticas e terminológicas inovadoras que adjetivam a proposta educacional, essas não dão conta de uma mudança substancial na perspectiva formativa.

No âmbito do IFPR, essas concepções são orientadas pelas finalidades institucionais de "promover a integração e a verticalização da educação básica à educação profissional e educação superior, otimizando a infraestrutura física, os quadros de pessoal e os recursos de gestão" e de "ofertar educação profissional e tecnológica, em todos os seus níveis e modalidades, formando e qualificando cidadãos com vistas à atuação profissional nos diversos setores da economia, com ênfase no desenvolvimento socioeconômico local, regional e nacional” (IFPR/REITORIA, 2017).

As licenciaturas em análise não contradizem as orientações legais e as institucionais, observando desde as diretrizes reguladoras da educação pelo Estado e pela autarquia ofertante. Por outro lado, elas se tornam desprovidas da crítica como autorreflexão formativa, quando se colocam apenas como meios formais para a superação de demandas sociais.

Sem negar o valor formativo das licenciaturas e sem desqualificar os projetos em questão, analisando-se o fundamento formativo, em aproximação com o sentido da formação cultural de Adorno, observa-se o reforço contínuo da pseudoformação cultural, ao mesmo tempo que a instituição se convence de que cumpre criticamente o seu papel formativo, ao dar ênfase ao desenvolvimento de competências.

O emprego do termo competência não pode ser analisado em si sem que seja compreendido em sua semântica. É fato que a palavra competência está envolta por uma série de concepções pedagógicas que mais dizem da operacionalização formativa do que a sua concepção originária (etimológica). Do latim competentĭa, o seu sentido refere-se à proporcionalidade e simetria das ações humanas e, como dado psicológico, diz sobre o que o indivíduo é na ação/relação, como atividade perceptível pelo coletivo. Como termo, a palavra competência serviu de referencial para fundamentar perspectivas pedagógicas (RAMOS, 2002) e construir cenários formativos. Assim, essa palavra expressa um conceito formativo nos PPCs, ao referendar o propósito educacional.

Observa-se nos PPCs analisados que a redação dos objetivos pretendidos expõe a visão sobre o processo educativo e a atuação dos docentes de Química e de Física em contextos reais. Esse elemento torna-se perceptível, quando se nota nos objetivos o apontamento para que os estudantes adquiram "a compreensão do mundo que os cerca, tanto o natural quanto o tecnológico" (IFPR/IVAIPORÃ, 2014, p. 17); para que possam desenvolver "a consciência da função social do professor" (IFPR/PARANAGUÁ, 2013, p. 4); para que adquiram "uma RIAEE - Revista Ibero-Americana de Estudos em Educação, Araraquara, v. 14, n. esp. 4, p. 2017-2031, dez., 2019. E-ISSN: 1982-5587. DOI: https://doi.org/10.21723/riaee.v14iesp.4.12925 
formação científica e humana abrangente, necessária para a atuação nas diversas vertentes da educação científica contemporânea" (IFPR/TELÊMACO BORBA, 2016, p. 13).

Concernentes aos objetivos desses PPCs, no que se refere à formação didáticopedagógica, o entendimento do mundo tecnológico implica uma crítica sobre a tecnologia como ferramenta do sistema produtivo. Contudo, não fica explícito nos PPCs a análise das contradições da própria tecnologia.

Nos objetivos do Curso de Física de Foz do Iguaçu, por exemplo, nota-se um potencial formativo para a crítica, quando expressa ser o curso "um ambiente educacional para a formação de educadores com capacidade crítica para as mudanças da sociedade brasileira e as diferentes formas de participação, orientados à construção de uma sociedade mais justa" (IFPR/FOZ DO IGUAÇU, 2013, p. 17). Esse objetivo aponta um certo esforço propositivo do curso em articular formação docente e ação social. Entretanto, sua postura em afirmar o sentido de "formar físico-educadores, capazes de fazer uso integrado das competências e habilidades implicadas na pesquisa e do ensino nas atividades educacionais diversas" corrobora a sua ligação com os escopos reguladores nacional e internacional, embasadas em diretrizes e orientações oficializadas pela orientação pseudoformativa.

No PPC de Química de Jacarezinho, um certo potencial autorreflexivo se manifesta em seu objetivo. O documento deixa claro o propósito de "formar o educador consciente de seu papel na formação de cidadãos sob a perspectiva educacional, científica, ambiental e social" e o de "gerar, por meio das atividades práticas e dos estágios curriculares vivenciados em diversos espaços educacionais, a integralização dos conhecimentos específicos com as atividades de ensino, pesquisa e extensão" (IFPR/JACAREZINHO, 2014, p. 12). O objetivo é assim exposto para dialogar com o perfil do egresso; contudo, mantém-se firmado na cultura formativa ao propor "competências e habilidades para que o formando tenha uma formação ampla, diversificada e sólida, em conhecimentos básicos das áreas específicas de Ciências Naturais e Química” (IFPR/JACAREZINHO, 2014, p. 12).

Também defende-se a indissociabilidade entre ensino, pesquisa e extensão, como ação articulada, mediante o seguinte argumento:

As estratégias propostas para a articulação desse tripé - ensino, pesquisa e extensão - se dará pela flexibilidade curricular que possibilita o desenvolvimento de atitudes e ações empreendedoras e inovadoras, tendo como foco as vivências da aprendizagem para a capacitação e para a inserção no mundo do trabalho (IFPR/JACAREZINHO, 2014, p. 21, grifo nosso). 
A análise faz notar que o escopo central do programa nessa dimensão formativa está voltado para duas ações: a "flexibilidade curricular" e o "desenvolvimento de atitudes e ações empreendedoras e inovadoras". Ambas se colocam como meios para a promoção da "aprendizagem para a capacitação e para a inserção no mundo do trabalho". Evidencia-se que não se extrapola a perspectiva de uma formação funcional. A indissociabilidade entre ensino, pesquisa e extensão tem seu potencial crítico e sua formação transformadora minimizados na construção argumentativa. As premissas justificadoras da indissociabilidade fundam-se em ações pedagógicas e didáticas que não contrariam a dinâmica formativa contemporânea, tampouco se colocam como resistência à ideologia hegemônica.

$\mathrm{Na}$ análise dos PPCs de cursos das licenciaturas em Física e em Química do IFPR, verifica-se que a objetividade argumentativa na construção dos projetos de cursos, por alguns campi, não se sobreleva como formação diferenciada daquela que oficialmente é implantada. Um possível projeto para uma formação diferenciada em relação às demais licenciaturas em execução poderia compor-se por reflexões explícitas e fundamentadas já na construção documental, a qual se apresenta como reguladora da ação didático-pedagógica e da filosóficocultural que confronta a realidade dada com o seu vir a ser. Tal postura ampliaria a concepção de fundamentos e de finalidades educativas em vista da construção histórico-social distinta da lógica vigente. Implica dizer que não é a criação de uma instituição que, por si, garante uma condição formativa diferenciada do socialmente padronizado e do economicamente estimulado.

Da perspectiva da Teoria Crítica da Sociedade, um processo educacional se consolida como formação cultural pela autocrítica da realidade e pela evidenciação dos meios e dos instrumentos que retiram do humano (em formação) a possibilidade de superar a identidade expropriada de si. Essa postura é tímida nos PPCs analisados. Não se diferenciando da condição assumida como marco oficial das licenciaturas, o sentido formativo esboçado nos PPCs coloca sobre o IFPR um limitador: o de legitimar a formação para a força de trabalho, apropriada para atender os anseios das organizações nacionais e internacionais. Seu principal desafio histórico consiste em fugir de uma formação para os iguais, isto é, de uma formação para a não mudança; de uma formação que inclui, mas que já exclui o cidadão da condição de ser mais do que mercadoria do processo produtivo; de um processo educativo adaptador do humano às habilidades e às competências elencadas como referências para o refletir e para o fazer didáticopedagógico. No processo formativo dos professores, por mais que haja a intencionalidade no IFPR de uma formação para a autonomia, tem-se impregnada, pela ausência da crítica autorreflexiva, os traços de um processo educativo envolvido pela pseudoformação. 
A tarefa de uma formação cultural, articulada com a formação específica e didáticopedagógica, é para promover o desenvolvimento humano, pois, sem ele, o crescimento social ou mesmo a sua mudança conceitual não ocorrem. Superar a conformidade, realçando a importância do 'não-idêntico' como premissa da autonomia e da emancipação, torna-se a tarefa primordial do IFPR por uma formação racional para além da cultura afirmativa, reprodutora das forças do sistema baseado na dominação e no controle.

\section{Considerações finais}

As reflexões apresentadas neste texto se referem a um conjunto de elementos que conduzem à percepção de que, no Brasil, a política institucionalizada pelo Estado para atender à demanda da formação de professores se desenvolve por meio de uma formação que, superficial, se presta à profunda consolidação de valores que atuam como mecanismos de repressão e de submissão, ou seja, que se contrapõem à democracia. Cabe, portanto, à reflexão crítica reinterpretar a formação e apontá-la para o sentido da autonomia em contraposição ao sistema social vigente e da ideologia que o subjaz.

Essa reflexão também pode ser compreendida no processo em que se constitui a pseudoformação oficializada. A proposta formativa que compreende a estrutura social do sistema capitalista (ADORNO, 1986) é identificada por Horkheimer e Adorno (1985, p. 20) como uma educação para a identidade conformista ou para o equivalente.

Uma vez que a sociedade burguesa é dominada pelo equivalente, ela torna o heterogêneo compatível, reduzindo-o a grandezas abstratas. A conformidade aqui é a aceitação do conjunto de produção que forma os bens culturais constituídos pela indústria cultural (ADORNO, 2009) e de um processo formativo que não o contraria, mas o alimenta incondicionalmente para a concretização do projeto reificador, portanto o da formação que, de certa forma, reitera o que se deveria combater: a heteronomia.

Trata-se de um saber e de um fazer científicos que coisificam os conteúdos objetivos da produção cultural, atribuindo-lhes o caráter de utilidade, de positivo, de mercadoria. A aceitação ou a refutação desses bens culturais estão ligadas à perspectiva do seu valor de consumo: aquilo (pensamento e ação objetificados) que tem mais valor cultural/comercial ou provoca maior interesse de satisfação pessoal e recebe maior ênfase em propostas de formação escolar em todas os níveis e âmbitos, inclusive em cursos de formação inicial e de formação continuada de professores. 
A identificação ou a conformidade/equivalência são categorias imanentes ao processo que fortalece e dissemina a pseudocultura pela educação institucional. Torna-se, portanto, uma cultura totalizadora ou universal (HORKHEIMER; ADORNO, 1985, p. 19), cujo indivíduo é elemento de sua manutenção. Assim, observa-se que o projeto para a formação de professores executado por instituições que compõem a Rede Federal de Educação Profissional e Tecnológica, configuradas em ações pedagógicas por meio dos PPCs, apresentam traços de um processo educativo alinhado aos interesses do capital, embora não deixe de apresentar brechas para a resistência.

Como em qualquer instância educativa, a tomada de consciência sobre o próprio processo formativo e sobre sua relação com os valores que alicerçam a sociedade e ao mesmo tempo dela advêm não é pouco diante da instrumentalização da razão - entrave para o pensar sobre a liberdade e a autonomia.

\section{REFERÊNCIAS}

ADORNO, T. W. Capitalismo tardio ou sociedade industrial? In: COHN, G. (Org.). Sociologia. São Paulo: Ática, 1986. ADORNO, T. W. Educação e emancipação. 4. ed. São Paulo: Paz e Terra, 2006.

ADORNO, T. W. Educação e emancipação. 4. ed. São Paulo: Paz e Terra, 2006.

ADORNO, T. W. Introdução à sociologia. São Paulo: Editora UNESP, 2008.

BANCO MUNDIAL. Aprendizagem para Todos: Investir nos conhecimentos e competências das pessoas para promover o desenvolvimento. Estratégia 2020 para a Educação do Grupo Banco Mundial. Resumo Executivo: 2011. Disponível em: http://siteresources.worldbank.org/EDUCATION/Resources/ESSU/4632921306181142935/Portguese_Exec_Summary_ESS2020_FINAL.pdf. Acesso em: 16 jun. 2019.

BRASIL. Educação profissional técnica de nível médio integrada ao ensino médio. Brasília: 2007. Disponível em: http://portal.mec.gov.br/setec/arquivos/pdf/documento_base.pdf. Acesso em: 16 jun. 2019.

BRASIL. Lei $\mathbf{n}^{\mathbf{0}}$ 11.502, de 11 de julho de 2007. Modifica as competências e a estrutura organizacional da fundação Coordenação de Aperfeiçoamento de Pessoal de Nível Superior CAPES, de que trata a Lei no 8.405, de 9 de janeiro de 1992; Disponível em: http://www.planalto.gov.br/ccivil_03/_ato2007-2010/2007/lei/111502.htm. Acesso em: 16 jun. de 2019.

BRASIL. Lei N. ${ }^{\circ} 11.892$, de 29 de Dezembro de 2008. Institui a Rede Federal de Educação Profissional, Científica e Tecnológica, cria os Institutos Federais de Educação, Ciência e Tecnologia, e dá outras providências. Diário Oficial da União, 30 dez. 2008. Disponível em: 
http://www.planalto.gov.br/ccivil_03/_ato2007-2010/2008/lei/111892.htm. Acesso em: 16 jun. 2019.

BRASIL. Instituto Federal de Educação, Ciência e Tecnologia. Um novo modelo em educação profissional e tecnológica: concepção e diretrizes. Brasília: MEC, 2010. Disponível em:

http://portal.mec.gov.br/index.php?option=com_docman\&view=download\&alias=6691-ifconcepcaoediretrizes\&Itemid=30192. Acesso em: 16 jun. 2019.

BRASIL. Lei no 13.005, de 25 de junho de 2014. Aprova o Plano Nacional de Educação PNE e dá outras providências. Diário Oficial da União, Brasília, DF, 26 jun. 2014.

BRASIL. Projeto de Lei N. ${ }^{\circ}$ 11.279, de 2019. Altera as Leis $n^{\circ} 11.892$, de 28 de dezembro de 2008; $n^{\circ} 12.706$, de 8 de agosto de 2012, e no 11.740, de 16 de julho de 2008; cria Institutos Federais de Educação, a Universidade Federal do Médio e Baixo Amazonas e a Universidade Federal do Médio e Alto Solimões, e dá outras providências. Disponível em: https://www.camara.leg.br/proposicoesWeb/prop_mostrarintegra;jsessionid=AF6A6EFDB89 C53C44D1DA5A20917D5EF.proposicoesWebExterno2?codteor $=1709922 \&$ filename=Avuls o+-PL+11279/2019. Acesso em: 16 jun. 2019.

CIAVATTA, M. A formação integrada: a escola e o trabalho como lugares de memória e de identidade. In: FRIGOTTO; CIAVATTA; RAMOS (Org.). Ensino médio integrado: concepções e Contradições. 3. ed. São Paulo: Cortez, 2012. p. 83-106, 2012.

COHN, G. Theodor W. Adorno. São Paulo: Editora Ática, 1986.

DELORS, J. Educação: um tesouro a descobrir. Relatório para a UNESCO da Comissão Internacional sobre a educação para o século XXI. Brasília/DF: UNESCO no Brasil, 1998. Disponível em: http://ftp.infoeuropa.eurocid.pt/database/000046001000047000/000046258.pdf. Acesso em: 16 jun. 2019.

HORKHEIMER, M.; ADORNO, T. W. Dialética do esclarecimento. Rio de Janeiro: Zahar, 1985.

IFPR/REITORIA. O instituto. Disponível em: http://reitoria.ifpr.edu.br/menuinstitucional/institucional/. Acesso em:16 jun. 2019.

IFPR-FOZ DO IGUAÇU. Projeto pedagógico de curso: licenciatura em física. Foz do Iguaçu: DEPE, 2013. Disponível em: http://foz.ifpr.edu.br/wp-content/uploads/2015/08/PPCCurso-de-Licenciatura-em-F\%C3\%ADsica.pdf. Acesso em: 15 jun. 2016

IFPR-IVAIPORÃ. Projeto pedagógico de curso: licenciatura em física. Ivaiporã: DEPE, 2014. Disponível em: http://ivaipora.ifpr.edu.br/wp-content/uploads/2017/02/PPCLicenciatura-em-F\%C3\%ADsica.pdf. Acesso em: 14 jun. 2016

IFPR-JACAREZINHO. Projeto pedagógico de curso: licenciatura em química. Jacarezinho: DEPE, 2014. Disponível em: http://jacarezinho.ifpr.edu.br/graduacao/licenciatura-emquimica/. Acesso em: 12 jun. 2019. 
IFPR-PARANAGUÁ. Projeto pedagógico de curso: licenciatura em física. Paranaguá: DEPE, 2013. Disponível em: http://paranagua.ifpr.edu.br/wp-content/uploads/2015/06/PPCLicenciatura-em-Fisica.pdf. Acesso em: 12 jun. 2019.

IFPR-REITORIA. O Instituto. Disponível em: http://reitoria.ifpr.edu.br/menuinstitucional/institucional/. Acesso em: 15 jun. 2019.

IFPR-TELÊMACO BORBA. Projeto pedagógico de curso: licenciatura em física. Telêmaco Borba: DEPE, 2016. Disponível em: http://telemaco.ifpr.edu.br/wpcontent/uploads/2012/11/PPC_F\%C3\%ADsica_Vers\%C3\%A3o10_2015.pdf. Acesso em: 15 jun. 2019.

MARCUSE, H. A ideologia da sociedade Industrial: o homem unidimensional. 4. ed. Rio de Janeiro: Zahar, 1973.

MARCUSE, H. A responsabilidade da ciência. In: Scientiæ Studia, São Paulo, v. 7, n. 1, p. 159-64, 2009. Disponível em: http://www.revistas.usp.br/ss/article/view/11170/12938. Acesso em: 16 jun. 2019.

MORIN, E.; CIURANA, E. R.; MOTTA, R. D. Educação na era planetária: O pensamento complexo como Método de aprendizagem no erro e na incerteza humana. São Paulo: Cortez, 2003.

RAMOS, M. N. A Pedagogia das Competências: autonomia ou adaptação? 2. ed. São Paulo: Cortez, 2002.

VIDAL, D. G. 80 anos do Manifesto dos Pioneiros da Educação Nova: questões para debate Diana Gonçalves Vidal. Educação e Pesquisa, São Paulo, v. 39, n. 3, p. 577-588, jul./set. 2013.

WIGGERSHAUS, R. A Escola de Frankfurt. História, desenvolvimento teórico, significação política. 2. ed. Rio de Janeiro: DIFEL, 2006.

\section{Como referenciar este artigo}

BIDO, José Mateus; GALUCH, Maria Terezinha Bellanda; CZYZEWSKI, Analice. Formação de professores no Instituto Federal do Paraná: dilemas formativos. Revista Ibero-Americana de Estudos em Educação, Araraquara, v. 14, n. esp. 4, p. 2017-2031, dez., 2019. E-ISSN: 1982-5587. DOI: https://doi.org/10.21723/riaee.v14iesp.4.12925

Data de submissão: $25 / 06 / 2019$

Data de aceite: 19/07/2019

Data de publicação: 01/09/2019 